in hormonal effects on brain and behavior, and for revealing mechanisms that confer sex-related differential risk for neuropsychiatric disorders. Moreover, the potential importance of such gene-hormone interactions suggests a general strategy for further exploration that may inform individualized treatments.

\section{FUNDING AND DISCLOSURE}

This work was supported by the Intramural Research Program of the National Institute of Mental Health, National Institutes of Health. The authors declare no competing interests.

\section{REFERENCES}

1. McEwen BS, Akama KT, Spencer-Segal JL, Milner TA, Waters EM. Estrogen effects on the brain: actions beyond the hypothalamus via novel mechanisms. Behav Neurosci. 2012;126:4-16.
2. Bath KG, Chuang J, Spencer-Segal JL, Amso D, Altemus M, McEwen BS, et al. Variant brain-derived neurotrophic factor (Valine66Methionine) polymorphism contributes to developmental and estrous stage-specific expression of anxiety-like behavior in female mice. Biol Psychiatry. 2012;72:499-504.

3. Spencer JL, Waters EM, Milner TA, Lee FS, McEwen BS. BDNF variant Val66Met interacts with estrous cycle in the control of hippocampal function. Proc Natl Acad Sci USA. 2010;107:4395-4400.

4. Wei SM, Baller EB, Kohn PD, Kippenhan JS, Kolachana B, Soldin SJ, et al. Brainderived neurotrophic factor Val66Met genotype and ovarian steroids interactively modulate working memory-related hippocampal function in women: a multimodal neuroimaging study. Mol Psychiatry. 2017;23:1066.

5. Epperson CN, Bale TL. BDNF Val66Met polymorphism and brain-derived neurotrophic factor levels across the female life span: implications for the sex bias in affective disorders. Biol Psychiatry. 2012;72:434-6.

6. Giza Jl, Kim J, Meyer HC, Anastasia A, Dincheva I, Zheng $\mathrm{Cl}$, et al. The BDNF Val66Met prodomain disassembles dendritic spines altering fear extinction circuitry and behavior. Neuron. 2018;99:163-78.

\title{
Sex differences in the incidence of antidepressant-induced mania (AIM) in bipolar disorders
}

\author{
Aislinn Williams ${ }^{1}$ and Melvin G. Mclnnis (iD) ${ }^{2}$ \\ Neuropsychopharmacology (2019) 44:224-225; https://doi.org/10.1038/s41386-018-0216-4
}

Bipolar disorder has similar prevalence between the sexes, but evidence suggests that men and women experience the disorder differently. Disorder onset, comorbidities, and treatment diverge significantly between men and women. For example, depressive episodes seem to predominate bipolar illness episodes in women, whereas in men, mania is more frequent [1]. There are also sex differences in management of medication side effects and comorbidities [2], and women with bipolar disorder report poorer sleep quality, which predicts more intense mood symptoms [3].

An oft-cited but poorly understood phenomenon in bipolar disorder is antidepressant-induced mania (AIM) or antidepressant emergent manic symptoms (AEMS). AIM describes the observation that hypomanic and manic symptoms can emerge when bipolar disorder patients use antidepressants, particularly when they are not taking a concurrent mood stabilizing medication. However, most bipolar disorder patients do not develop AIM when exposed to antidepressants, and the current data suggest that the risk factors for AIM in men and women may differ [4]. Clinicians routinely screen for AIM when treating bipolar depression with antidepressants, but little is known about which demographic and clinical variables increase risk for AIM, and even less is known about gender-specific risk factors.

In our retrospective study of 416 patients with bipolar disorders, we found that women were more likely to receive antidepressants than men [5]. This is in agreement with data from Karanti et al. [6] who showed that women with bipolar disorder were more likely to be prescribed antidepressants than men, which was independent of illness severity or other clinical factors. Strikingly, in our sample, female sex was the only variable that emerged from regression modeling as a statistically significant risk factor for AIM. In another recent study, Scott et al. [4] identified a number of factors that convey differential risk for AIM between men and women. They reported that male AIM patients were more likely to have an alcohol or substance use disorder, a history of suicide attempt(s), and a greater number of depressive episodes per year. Female AIM patients were more likely to have a history of thyroid disorder, family history of bipolar disorder type I, or a depressive episode at the onset of bipolar illness.

These early findings of differences between men and women with bipolar disorder, and how this may affect the incidence of AIM, are compelling and merit further study. Tools for identifying patients at highest risk would be very helpful, particularly since the incidence of AIM is low (generally estimated to be $\sim 10-20 \%$ of bipolar disorder patients who take antidepressants) but the dangers of mania are significant. It is unclear whether the observed treatment and outcome discrepancies between men and women with bipolar disorder are due primarily to physiological differences between sexes (e.g., hormonal pathways, sexspecific neuronal circuitry), or as described in Karanti et al [6], have less basis in physiology and more to do with disparities in how physicians treat women and men (Fig. 1).

\section{FUNDING:}

This work was supported by NIH UL1TR002240, the HC Prechter Bipolar Research Program and the Richard Tam Foundation of the University of Michigan, the Department of Psychiatry and Depression Center of the University of Michigan.

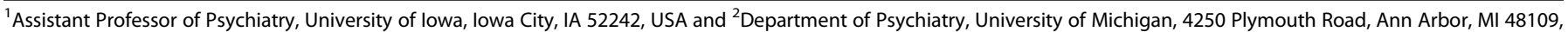
USA

Correspondence: Melvin G. McInnis (mmcinnis@umich.edu)

Published online: 28 September 2018 


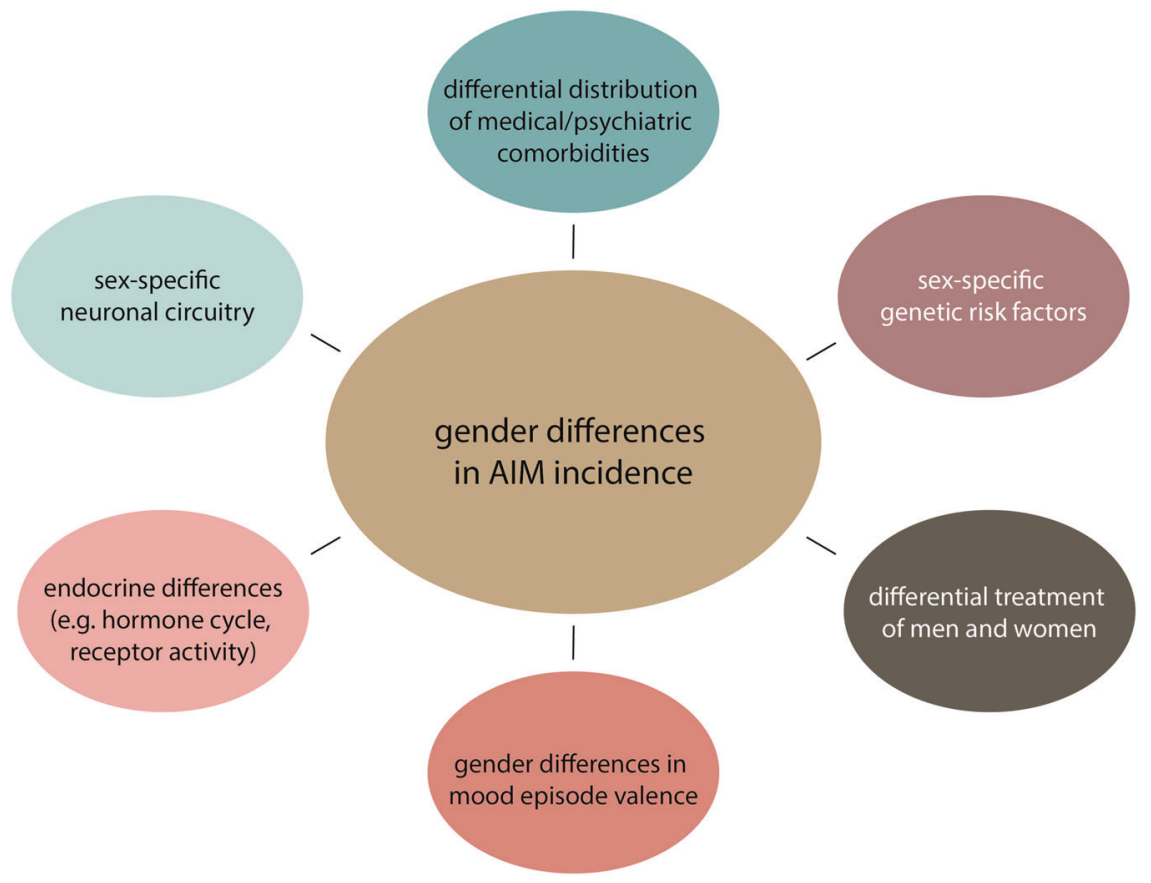

Fig. 1 Potential factors that contribute to gender differences in antidepressant-induced mania

Competing interests: MGM has received consulting income and research funding from Janssen Pharmaceuticals. The remaining author declares that they have no conflict of interest.

Publisher's note: Springer Nature remains neutral with regard to jurisdictional claims in published maps and institutional affiliations.

\section{REFERENCES}

1. Azorin JM, Belzeaux R, Kaladjian A, Adida M, Hantouche E, Lancrenon S, et al. Risks associated with gender differences in bipolar I disorder. J Affect Disord. 2013;151:1033-40

2. Svendal G, Fasmer OB, Engeland A, Berk M, Lund A. Co-prescription of medication for bipolar disorder and diabetes mellitus: a nationwide population-based study with focus on gender differences. BMC Med. 2012;10:148.
3. Saunders EF, Fernandez-Mendoza J, Kamali M, Assari S, Mclnnis MG. The effect of poor sleep quality on mood outcome differs between men and women: A longitudinal study of bipolar disorder. J Affect Disord. 2015;180: 90-6.

4. Scott J, Brichant-Petitjean C, Etain B, Henry C, Kahn JP, Azorin JM, et al. A reexamination of antidepressant treatment-emergent mania in bipolar disorders: evidence of gender differences. Acta Psychiatr Scand. 2017;135:479-88.

5. Williams AJ, Lai Z, Knight S, Kamali M, Assari S, Mclnnis MG. Risk factors associated with antidepressant exposure and history of antidepressant-induced mania in bipolar disorder. J Clin Psychiatry 2018;79:17m11765.

6. Karanti A, Bobeck C, Osterman M, Kardell M, Tidemalm D, Runeson B, et al. Gender differences in the treatment of patients with bipolar disorder: a study of 7354 patients. J Affect Disord. 2015;174:303-9.

\section{Guidance cues: linking drug use in adolescence with psychiatric disorders}

Lauren M. Reynolds $\mathbb{D}^{1,2}$ and Cecilia Flores ${ }^{2}$

Neuropsychopharmacology (2019) 44:225-226; https://doi.org/10.1038/s41386-018-0221-7

Adolescent onset of drug use is associated with an enduring elevation in the risk of progressing from recreational use to addiction. Unfortunately, adolescent experimentation with drugs of abuse remains common, with more than half of initiates under the age of 18 years old. This peak age for drug initiation coincides with a critical developmental period for

\footnotetext{
${ }^{1}$ Integrated Program in Neuroscience, McGill University, Montréal, QC, Canada and ${ }^{2}$ Department of Psychiatry and Department of Neurology and Neurosurgery, McGill University, Douglas Mental Health University Institute, Montréal, QC, Canada

Correspondence: Cecilia Flores (cecilia.flores@mcgill.ca)
}

Received: 24 July 2018 Accepted: 5 September 2018

Published online: 1 October 2018 